\title{
Volatile Substances from Male Anastrepha fraterculus Wied. (Diptera: Tephritidae): Identification and Behavioural Activity
}

\author{
Ivanildo S. Lima ${ }^{a *}$, Philip E. House ${ }^{b}$ and Ruth R. do Nascimento ${ }^{c}$ \\ ${ }^{a}$ Departamento de Fitotecnia e Fitossanidade, Universidade Federal de Alagoas, \\ Campus Delza Gitaí, BR 104 Norte Km 85, 57120-000, Rio Largo - AL, Brazil \\ ${ }^{b}$ Department of Biology, University of Southampton, Bassett Crescent East, Southampton, SO16 7PX - U.K. \\ ${ }^{c}$ Departamento de Química, Universidade Federal de Alagoas, BR 104 Norte Km 14, 57072-970, Maceió - AL, Brazil
}

\begin{abstract}
Substâncias voláteis produzidas por machos do gênero Anastrepha foram isoladas previamente de A. ludens e A. suspensa. Ambas as espécies acasalam no período da tarde, liberam compostos similares em diferentes proporções e apenas diferem na produção de monoterpenos. Quando estão em chamamento, os machos de A. fraterculus liberam dois isômeros do sesquiterpeno $\alpha$-farnesene, três lactonas (anastrefin, epianastrefin e $(E, E)$-suspensolídeo) e dois monoterpenos (limoneno e (Z)-ß-ocimeno). As glândulas salivares dimórficas dos machos produzem e/ou armazenam os mesmos isômeros do $\alpha$-farnesene e suspensolídeo, e quatro pirazinas. Dois desses compostos foram previamente isolados de machos de A. ludens e A. suspensa. Em bioensaios, as glândulas salivares de machos de A. fraterculus atraíram as fêmeas virgens e sexualmente ativas. No entanto, as fêmeas sexualmente imaturas não mostraram atividade comportamental.
\end{abstract}

Volatile compounds produced by calling males of Anastrepha species have previously been reported from $A$. ludens and $A$. suspensa. Both species mate in the afternoon, release a similar range of compounds in different proportions, and only differ in the production of monoterpenes. When calling, male $A$. fraterculus releases two isomers of the sesquiterpene $\alpha$-farnesene, three lactones (anastrephin, epianastrephin and (E,E)-suspensolide), and two monoterpenes (limonene and (Z)- $\beta$-ocimene). The dimorphic male salivary glands produce and/or store the same isomers of $\alpha$-farnesene and suspensolide, and four pyrazines. Two of these compounds have been previously reported from male A. ludens and A. suspensa. Salivary glands from virgin calling male A. fraterculus showed behavioural activity when bioassayed with virgin mature female flies, but immature females were not attracted.

Keywords: Anastrepha, fruit fly, volatiles, behaviour, terpenes, lactones

\section{Introduction}

Fruit flies of the genus Anastrepha (Diptera: Tephritidae) include 150 to 200 species native to the Caribbean, Mexico and Latin America. Due to their high biotic potential, large number of host plants, rapid establishment and development, fruit flies have become serious pests of many fruit trees and vegetables in temperate, sub-tropical and tropical areas. The damage to crops caused by fruit flies can be either direct, through oviposition in fruit and tissues of vegetative parts of plants and feeding by the larvae, or indirect, through decomposition of plant tissues by invading microorganisms and quarantine restrictions 1 .

\footnotetext{
*e-mail: isl@fapeal.br
}

During calling activity males of several Anastrepha species produce and release volatile substances. These volatiles are released from the mouth and anus and possibly by evaporation from the cuticular body surface ${ }^{1}$. Volatile compounds produced by males have previously been identified only from A. ludens and A. suspensa. Pheromone components of male flies of these two species were obtained from whole body extracts, abdominal extracts and by aeration ${ }^{2-7}$. Males $A$. ludens and A. suspensa release different proportions of the same three sesquiterpene hydrocarbons: $\alpha$-farnesene, $\beta$-bisabolene and $\alpha$-transbergamotene. The chemical composition of the mixture released by calling males of both species has been shown to be species-specific; male $A$. suspensa produce the monoterpene $(Z)$ - $\beta$-ocimene while male $A$. ludens produce limonene ${ }^{5}$. After bioassay of male abdominal extracts of 
A. ludens, Robacker ${ }^{8}$ and Garcia suggested that (Z)-3nonenol, (Z,Z)-3,6-nona-dienol, (-)-(S,S)- epianastrephin, and (-)-(S,S)-anastrephin are all components of the sex pheromone. Chuman ${ }^{4}$ and co-workers isolated a macrolide from male A. suspensa which was identified as (E,E)-4,8-dimethyl-3,8-decadien-10-olide. The presence of (E,E)-3,8-suspensolide as a major component of the volatile mixture emitted by male A. ludens was first reported by Rocca ${ }^{5}$ and co-workers.

Beneath the lateral abdominal pouches of many tephritids there are two male-specific glands, the pleural glands and the male dimorphic salivary glands. Male salivary glands of several Anastrepha species, including the South American fruit fly A. fraterculus, arise from a common duct in the head which bifurcates into two lateral tubes that extend down each side of the abdomen and end as a large ball of coiled tubules ${ }^{9}$. When calling, male $A$. fraterculus inflate the pleural pouches in which the reservoir of the salivary glands, which are believed to produce sex pheromone, is located. The aeration technique is considered the best method for collecting pheromone from live insects, as it avoids extraction of impurities present in glands and tissue extracts ${ }^{10}$. However, there is evidence from studies on isolated male glands and tissue analysis, that chemical compounds such as lactones and sesquiterpenes are produced or stored in the male salivary glands of many tephritid fruit fly species. The aim of this research was to isolate and identify volatile compounds from calling male A. fraterculus and to study the responses of sexually immature and mature female flies to different concentrations of male salivary glands.

\section{Experimental}

\section{Insects}

The culture of A. fraterculus was established as pupae from CPACT/EMBRAPA, southern Brazil. Adult flies A. fraterculus were obtained from a laboratory colony at University of Southampton, where they had been in culture for three generations. Male flies were segregated on the day they emerged, fed with muscovado sugar and water. The rearing and the experimental room were maintained at $26 \pm 2{ }^{\circ} \mathrm{C}, 60 \pm 10 \% \mathrm{RH}$ and 13:11 $\mathrm{h}$ LD photoperiod at 1600 lux with a $1 \mathrm{~h}$ at 15 lux dawn and dusk.

\section{Salivary glands}

Salivary glands of twenty virgin calling males, aged 18 to 25 days, were removed and placed in a glass vial containing dichloromethane for liquid sample analysis. The sample was then concentrated to a volume of approximately
$100 \mu \mathrm{l}$ and stored until chemical analysis. Salivary glands of calling males were also dissected out and sealed in groups of 3 or 5 male equivalents (ME), in soft glass capillaries for solid sample analysis ${ }^{11}$. The samples were stored in a freezer until chromatography.

\section{Collection of volatiles from male flies}

Volatiles emitted by virgin calling male flies were collected using an air entrainment apparatus as described by Golub $^{12}$ and Weatherson. A humidified and purified airstream was passed over live males in a glass chamber (43 $\mathrm{cm}$ length $\mathrm{x} 6 \mathrm{~cm}$, o.d.). The volatile compounds emitted by the insects were trapped onto $150 \mathrm{mg}$ of Tenax ${ }^{\circledR}(60-80$ mesh) which was used as an adsorbent for trapping the pheromones. Activated charcoal (4-14 mesh) was used for the purification of the airstream. The air intake filter was activated by heating with a bunsen burner while nitrogen gas flowed through it (ca. $25 \mathrm{ml} / \mathrm{min}$ ). The pheromone collection trap was cleaned by washing first with hexane to remove non-polar contamination and subsequently with methanol to remove polar contamination. After using each solvent the tenax trap was allowed to dry at room temperature in a gas chromatograph (GC) oven with nitrogen flowing through it. The trap was then heated for 3 hours in a GC oven at $280^{\circ} \mathrm{C}$ using nitrogen gas flow to avoid desiccation. The volume or mass flow was ca. $1 \mathrm{~L} \cdot \mathrm{min}^{-1}$, flowing constantly and measured with an airflow meter (ELE International ltd EL 503-070). All glassware used was previously washed in 5\% "Decon 90", rinsed with distilled water and dried in an oven. Virgin male flies were transferred from the culture room to the experimental room one day before aeration, and placed in the glass aeration chamber just before dusk. The aeration was carried out from the beginning of the dawn period, using 80 males aged between 15 and 30 days, and lasted for $3.5 \mathrm{~h}$. After aeration, the volatile compounds trapped on the tenax were extracted by solvent desorption with $10 \mathrm{ml}$ of distilled hexane. The extract was then concentrated to approximately $100 \mu \mathrm{l}$ by passing nitrogen gas over it and stored in a freezer until analysis.

\section{Aeration for thermal-desorption analysis}

After diluting glands in solvent, or when concentrating to a very small volume, volatile substances may be lost or may be below the limit of detection ${ }^{11}$. To minimize this problem, the aeration was carried out using, as volatile collection trap, a glass tube $(40 \mathrm{~cm}$ length $\times 1.0 \mathrm{~cm}$, o.d.) to allow its placement inside an electrically-heated oven provided with a controllable range of temperature, and directly connected with the GC column. $100 \mathrm{mg}$ of tenax 
(60-80 mesh) was used as the adsorbent for trapping the volatiles. After aeration the insect holding chamber was thoroughly washed with distilled hexane to collect lessvolatile substances, which could remain impregnated on the interior glass surface of the chamber. This extract was then concentrated to $100 \mu \mathrm{l}$ by passing nitrogen gas over it and stored in a freezer.

\section{Instrumentation}

\section{Gas chromatography-mass spectrometry}

Hexane extracts of salivary glands of virgin male $A$. fraterculus and pure salivary glands were analysed on a Hewlett-Packard 5890 gas chromatograph coupled to a 5970 B Mass Selective Detector (MSD) system using 70 eV electron impact ionisation with the GC capillary column connected directly to the ion source.The operating parameters were controlled by an HP series 300 computer with an HP 59970 C ChemStation. Chromatography was performed on an immobilized polydimethylsiloxane phase (equivalent to $\mathrm{OV}-1)$ in a fused silica column (12 m length $\mathrm{x} 0.22 \mathrm{~mm}$ i.d. $\mathrm{x} 0.33 \mu \mathrm{m}$ film thickness). Helium was used as the carrier gas at a linear flow rate of $1 \mathrm{ml} / \mathrm{min}$. The samples were heated in the injection port at $150{ }^{\circ} \mathrm{C}$. The oven temperature was programmed from $30^{\circ} \mathrm{C}$ for $2 \mathrm{~min}$, then it was allowed to rise at a rate of $8^{\circ} \mathrm{C} / \mathrm{min}$ to $150^{\circ} \mathrm{C}$.

\section{Thermal-desorption}

After aeration the collection trap was placed inside an electrically-heated oven directly connected with the GC injection port. The adsorption tube was heated to $250{ }^{\circ} \mathrm{C}$ for $20 \mathrm{~min}$ while a helium gas at a linear flow rate of $15 \mathrm{ml} / \mathrm{min}$ was passed through the trap. The outlet was connected to a glass-lined steel tube (SGE, Milton Keynes, U.K.), bent to form a U-tube and cooled in that portion by immersion in liquid nitrogen in a Dewar flask. From the U-tube, the glass-lined metal was inserted through a hole in the GC injection port, finishing at the heated zone of the injection block. When all the volatiles had been desorbed from the tenax and collected in the U-tube, the glasslined tube was flash-heated to $250^{\circ} \mathrm{C}$ by passing a direct current through the metal covering and the plug of organic compounds was swept on to the chromatographic column. The GC oven temperature was programmed from $30{ }^{\circ} \mathrm{C}$ and held at this temperature for $2 \mathrm{~min}$, then it was allowed to rise at a rate of 8 ${ }^{\circ} \mathrm{C} / \mathrm{min}$ to $280^{\circ} \mathrm{C}$.

\section{Chemical identification}

The majority of the chemicals were identified by comparison of GC retention times and mass spectra fragmentation patterns with authentic synthetic standards. For spectral confirmations, commercial compounds were coinjected on the GC column. However, where standard compounds were not available the identification was carried out by comparison with reference spectra such as the Registry of mass spectral data ${ }^{13}$ and those given by Rocca ${ }^{5}$ and co-workers.

\section{Behavioural activity}

In order to test the attractiveness of male salivary glands to virgin mature ( 25 to 30 days old) and immature (1 to 10 days old) female $A$. fraterculus, a polystyrene box $(28 \mathrm{x} 10 \mathrm{x}$ $15 \mathrm{~cm}$ ) was used as a bioassay chamber. For each replicate, 20 virgin females were introduced into the bioassay chamber one day before the experiment and used only once per replicate. Original datas were transformed by $\log$ (response + 1) and a one-way ANOVA followed by Tukey's multiple range test was applied to identify significant differences. Salivary glands were obtained by dissecting virgin male flies aged 25 to 30 days during the dawn period. Fresh dissected salivary glands were placed on a filter paper, introduced in the bioassay chamber, and placed over another filter paper positioned half way down one side of the chamber. A filter paper with a droplet of filtered water was placed in a similar position on the opposite side of chamber to act as a control. Two doses replicated 11 times were tested: $1 \mathrm{ME}$ and $5 \mathrm{ME}$. Student's paired $t$ test was used to identify significant differences.

\section{Results}

\section{A. fraterculus volatiles}

Figure 1 shows the partial identification of the volatile compounds present in the liquid sample of male salivary glands of $A$. fraterculus. Peaks labelled 1,2 and 3, represent the sesquiterpene $(E, Z)-\alpha$-farnesene, the lactone $(E, E)-\alpha$ suspensolide, and the sesquiterpene $(Z, E)$ - $\alpha$-farnesene, respectively. The volatiles collected by washing the insect holding chamber with hexane after aeration is presented in Figure 2. Peak 1 represents the sesquiterpene $(E, Z)-\alpha$ farnesene and peak 2 the sesquiterpene $(Z, E)-\alpha$-farnesene. The fragmentation patterns of peak $\mathbf{3}$ and $\mathbf{4}$ were compared with published spectra ${ }^{14}$, and identified as anastrephin and epianastrephin. Both lactones were also identified by comparing their retention times and fragmentation patterns with those obtained from a sample of aerated extract of male $A$. suspensa, which was kindly provided by Dr J.L. Nation. The lactone $(E, E)$-suspensolide was identified by comparison of the mass spectrum fragmentation pattern with that presented by Rocca ${ }^{5}$ and co-workers, who found suspensolide in the mixture of 


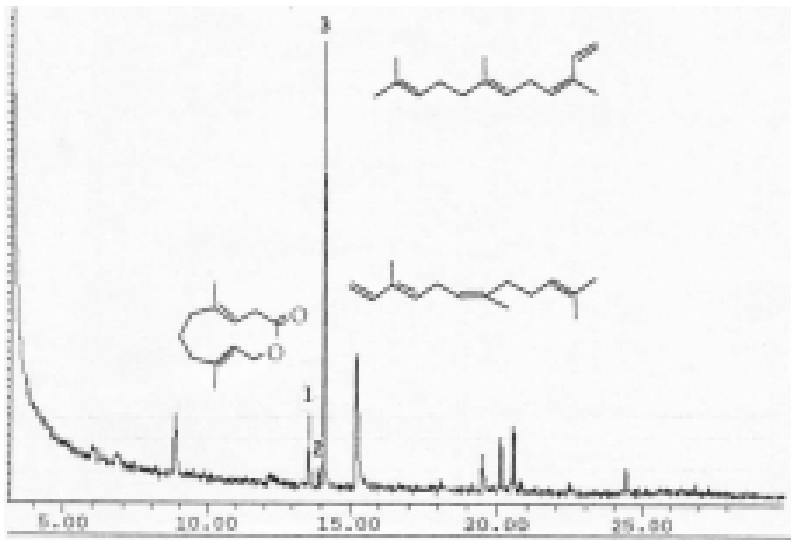

Figure 1. Gas chromatogram of the volatile compounds present in the salivary glands of calling male $A$. fraterculus. Peaks are numbered according to their elution order. 1) $(E, Z)$ - $\alpha$-farnesene; 2) $(E, E)$ suspensolide; 3) (Z,E)- $\alpha$-farnesene (liquid sample).

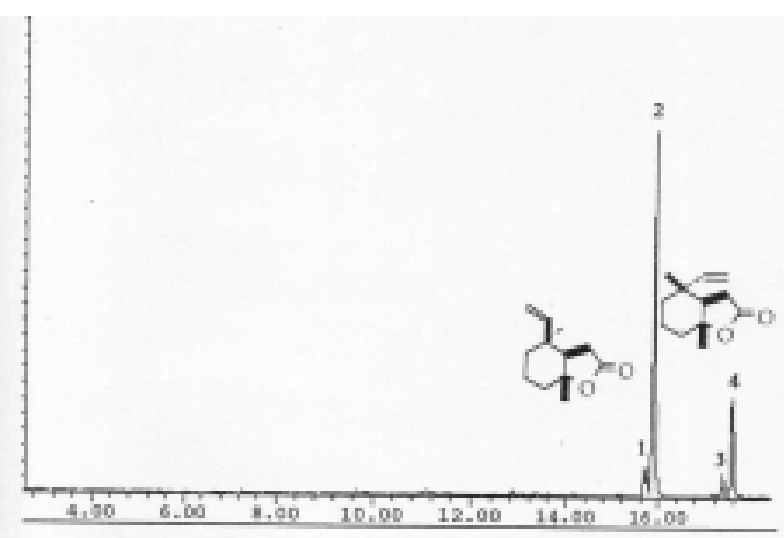

Figure 2. Gas chromatogram of the volatile compounds collected by washing the insect holding chamber with solvent after aeration of male A. fraterculus. Peaks are numbered according to their elution order. 1) $(E, Z)$ - $\alpha$-farnesene; 2) (Z,E)- $\alpha$-farnesene; 3) anastrephin; 4) epianastrephin.

volatiles emitted by males $A$. ludens. The isomers of the sesquiterpene $\alpha$-farnesene were identified by comparison with authentic synthetic standards.

Chemical analysis of the solid sample revealed the presence of several pyrazines in very small amounts, which could not be identified by analyzing liquid samples or thermal desorption (Figure 3). Peaks labelled 1, 2, 3, and 4, represent 2,5-dimethylpyrazine, 2,3,5-trimethylpyra-zine, 3-ethyl-2,5dimethylpyrazine, and 3-butyl-2,5-dimethylpyrazine. Peaks 5 and 6 represent $(E, Z)$ and $(Z, E)$ - $\alpha$-farnesene, respectively. The pyrazines were identified by comparison with authentic synthetic standards. The volatile compounds trapped on to tenax, without the use of solvent, showed the presence of two previously unrecorded compounds, which were identified as limonene and cis- $\beta$-ocimene, peaks $\mathbf{1}$ and $\mathbf{2}$ in Figure 4. These compounds were also identified by comparison with authentic synthetic standards.

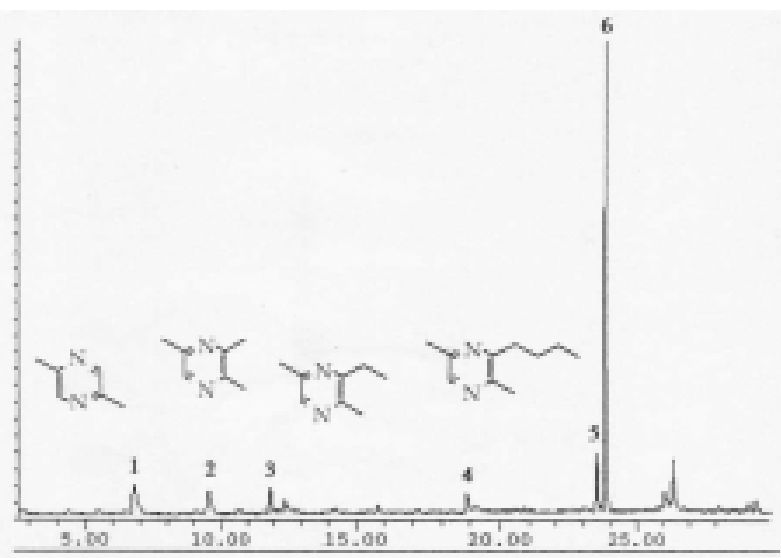

Figure 3. Gas chromatogram of the volatile compounds present in the salivary glands of calling male A. fraterculus. Peaks are numbered according to their elution order. 1) 2,5-dimethylpyrazine; 2) 2,3,5trimethylpyrazine; 3) 3-ethyl-2,5-dimethylpyrazine; 4) 3-butyl-2,5dimethylpyrazine; 5) (E,Z)- $\alpha$-Farnesene; 6) $(Z, E)$ - $\alpha$-Farnesene (solid sample).

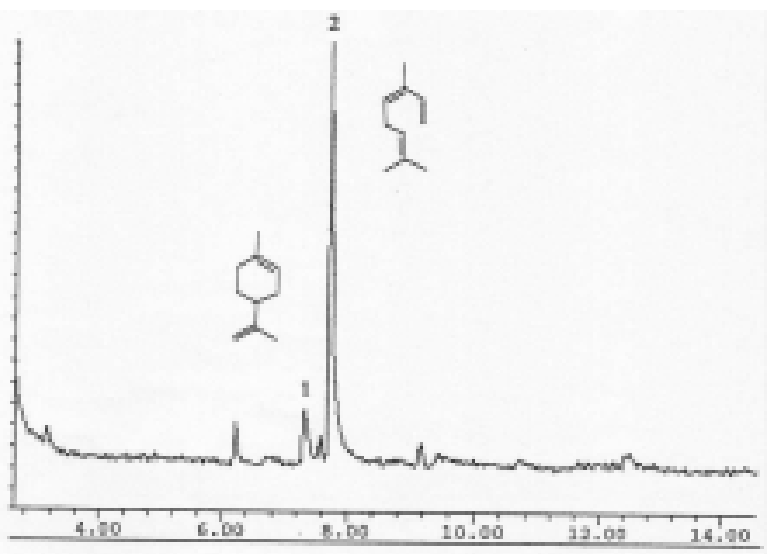

Figure 4. Gas chromatogram of the volatile compounds present in the salivary glands of calling male $A$. fraterculus trapped on to tenax. Peaks are numbered according to their elution order. 1) limonene; 2) cis- $\beta$ ocimene (thermal desorption).

\section{Behavioural activity}

Salivary glands of male flies were attractive and acted as an arrestant for mature virgin females. The mean log responses of virgin mature females to two doses of male salivary glands are given in Figure 5. The mean time for the first female to arrive, and the mean time spent probing on the source were significantly higher for the dose of 5 $\mathrm{ME}=$ male equivalents than those recorded for the dose of $1 \mathrm{ME}$ (Figure 6). As virgin immature females were not attracted to male salivary glands, another bioassay was carried out in order to determine the female age response threshold to male salivary glands. Two groups of 20 females were continuously bioassayed with $1 \mathrm{ME}$ and $5 \mathrm{ME}$, from the third day after adult emergence, until the day on which 


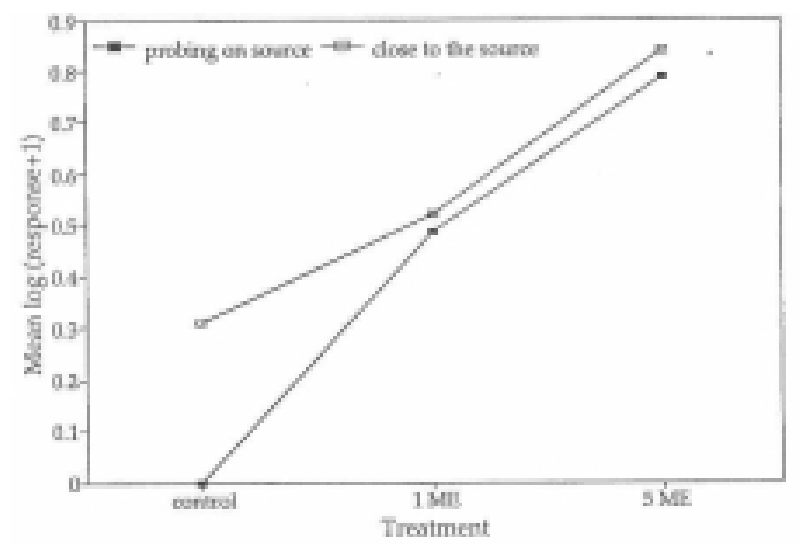

Figure 5. Behavioural responses of virgin mature female $A$. fraterculus to two concentrations of male salivary glands. Data were transformed by $l o g$ (response + 1). $5 \mathrm{ME}$ elicited a highly significant response for female probing and close to the source. Tukey's multiple range test $(P<0.001)$. Standard errors are too small to be shown.

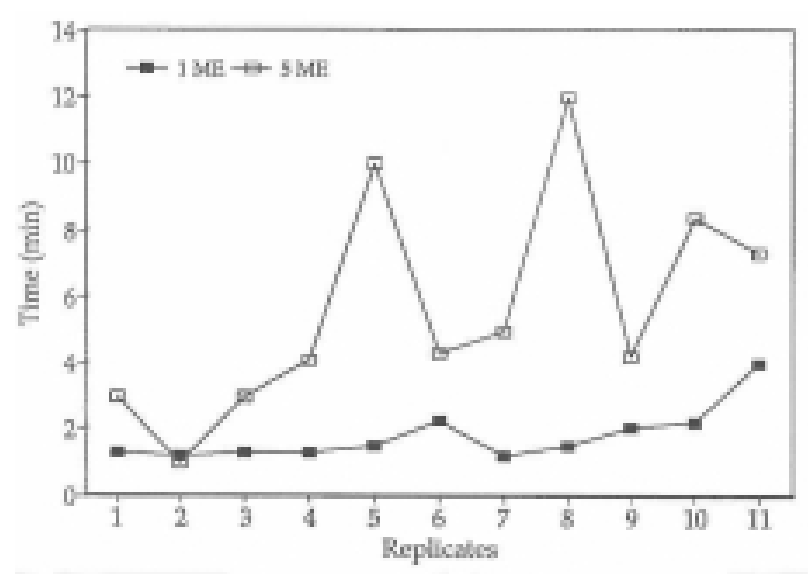

Figure 6. Time spent by virgin mature female A. fraterculus probing in the presence of two different concentrations of male salivary glands. Mean probing time is $5.6 \mathrm{~min}$ and $1.8 \mathrm{~min}$ for the doses of 5 male equivalents (ME) and $1 \mathrm{ME}$ respectively. (highly significant at $P<0.001$, Student's paired $t$ test).

the first probing behaviour was observed. The results of these observations led us to believe that female flies were attracted to salivary glands of calling males only when they reached sexual maturation, which is on average 16 days old ${ }^{15}$.

\section{Discussion}

When concentrating to a very small volume, volatile substances may be lost or may be below the limit of detection $^{11}$. Two other factors have been reported as the main reasons for the loss of very volatile substances. When using tenax as adsorbent ${ }^{7}, 25 \%$ of suspensolide was lost and the elevated temperatures of GC detector, commonly used with split-splitless injections, resulted in an additional loss of approximately $75 \%$ of the same compound. In spite of several unsuccessful attempts for trapping volatiles from male A. fraterculus, it was possible to identify the monoterpenes limonene, which has been reported only for A. ludens, and cis-B-ocimene, reported only for A. suspensa. Both lactones (anastrephin and epianastrephin) here reported for A. fraterculus are also present in A. ludens and $A$. suspensa ${ }^{3,6,14}$. Analysis of the mass spectra from the liquid sample of salivary glands of male A. fraterculus led to the identification of two isomers of a sesquiterpene hydrocarbon and one lactone, $(Z, E)-\alpha$-farnesene, $(E, Z)-\alpha$ farnesene and $(E, E)$ - suspensolide respectively. These volatiles are reported here for the first time for $A$. fraterculus, but have been previously reported as volatile components of $A$. ludens and $A$. suspens $a^{4,5}$. In both methods of analysis (i.e. liquid and solid sample) the major compound found in the male salivary gland was $\alpha$-farnesene. Some of the compounds released by male $A$. ludens and A. suspensa are present in the male salivary glands of $A$. fraterculus. However, $\alpha$-trans-bergamotene, which is a minor component for A. ludens and also present in A. suspens $a^{5}$, were not found in the male salivary glands of $A$. fraterculus. Neither the sesquiterpene B-bisabolene was detected, nor the two nonenols reported by Nation ${ }^{2}$ from A. ludens. Epianastrephin, which is a major component of $A$. ludens and $A$. suspensa and anastrephin, reported as being a minor component for both species, were detected in A. fraterculus, only when the insect aeration chamber was washed up with hexane.

Analysis of the solid samples, however, revealed the presence of several pyrazines that have not been reported as volatile components of any other Anastrepha species. Pyrazines have been detected in volatiles from protein hydrolysate $^{16}$, in ant alarm and trail pheromones ${ }^{17,18}$, and also as volatile components of other tephritid fruit flies, including Ceratitis capitata, Bactrocera curcubitae, B. dorsalis and Toxotrypana curvicauda ${ }^{19-21}$. The pyrazines here reported may be essential components of the pheromone blend, or even important precursors of other volatiles released during calling activity.

The similarity of the volatiles produced by males of the genus Anastrepha and the correspondingly similar courtship behaviour displayed during pheromone release suggests an interesting and close evolutionary relationship. Rocca ${ }^{5}$ and co-workers have suggested that A. ludens and A. suspensa may have had a common ancestor that became fragmented due to environmental change. As both species mate in the afternoon, the differences in their terpenes (limonene and ocimene) could be a mechanism for reproductive isolation. The complete range and relative proportions of the volatiles produced and released by males $A$. fraterculus has not yet been determined, but the results here reported showed 
the presence of limonene and ocimene. Therefore, it could only be speculated that $A$. fraterculus also had the same ancestor of $A$. ludens and A. suspensa, and as mating initiation occurs in the first hours of the day, male $A$. fraterculus still remain producing both terpenes during calling activity. Additional information from laboratory and field experiments could provide a more reasonable evolutionary significance of the volatiles here reported.

Male salivary glands were highly attractive in laboratory bioassays to virgin mature females. Our experiments indicate that these glands are not only attractants at close range, but also have an arrestant effect on females. Females spent up to 12 min (maximum) probing on the source. Probing was interrupted only when a female attempted to repel another approaching female. Even when they were probing in groups of three or four, flies did not stop fighting among themselves.

\section{Conclusion}

When calling, male $A$. fraterculus releases two isomers of the sesquiterpene $\alpha$-farnesene, the lactones anastrephin, epianastrephin and suspensolide and two monoterpenes, limonene and $\beta$-ocimene. In both methods of analysis the major compound found in the male salivary gland was $\alpha$-farnesene. Male salivary glands produce and/or store at least four pyrazines. Anastrephin and epianastrephin were obtained only by washing the insect holding chamber with hexane after aeration. This finding suggests that both lactones are not very volatile. The pyrazines may be essential components of the sex pheromone blend, or even important precursors of other volatiles released during calling activity. At least three observations led us to believe that male salivary glands do not act as a food attractant: a) in all replicates the experimental flies were supplied with a separate source of food; b) immature females were not attracted to the salivary glands, and c) previous studies have shown that flies did not display territorial behaviour on the source of food. Data on the mean age of female $A$. fraterculus that responded to male salivary glands confirmed that only sexually mature females were attracted.

\section{Acknowledgments}

We gratefully acknowledge financial support from the Conselho Nacional de Desenvolvimento Científicoe Tecnológico (CNPq/RHAE-Brazil), grant no. 260087/90.4. This work was carried out under MAFF licence no. PHF 1157/705/83 issued under the Import and Export (Plant Health) (Great Britain) Order 1908 and the Plant Pests (Great Britain) Order 1980.

\section{References}

1. Nation, J. L. In World crop pests: fruit flies, their biology, natural enemies and control. Robinson, A. S.; Hooper, G. H. S., Eds.; Elsevier; Amsterdam, 1989, p 189.

2. Nation, J. L. Environ. Entomol. 1975, 4, 27.

3. Battiste, M. A.; Strekowski, L.; Vanderbilt, D. P.; King, R. W. Tetrahedron Lett.1983, 24, 2611.

4. Chuman, T.; Sivinski, J.; Heath, R. R.; Calkins, C. O.; Tullinson, J. H. Tetrahedron Lett. 1988, 29, 6561.

5. Rocca, J. R.; Nation, J. L.; Strekowski, L.; Battiste, M. A. J. Chem. Ecol. 1992, 18, 223.

6. Epsky, N. D.; Heath, R. R. Environ. Entomol. 1993, 22, 464.

7. Heath, R. R.; Manukian, A.; Epsky, N. D.; Sivinski, J.; Calkins, C. O.; Landolt, P. J. J. Chem. Ecol. 1993, 19, 2395.

8. Robacker, D. C.; Garcia, J. A. J. Chem. Ecol. 1990, 16, 2027.

9. Nation, J. L. Int. J. Insect. Morphol. Embryol. 1981, 10, 121.

10. Nation, J. L. In Proc. Int. Symp. Biol. Control of Fruit flies. Kawasaki, K.; Iwahashi, O.; Kaneshiro, K.Y., Eds.; Ginowan; Okinawa; Japan, 1991, p 233.

11. Morgan, E. D. Anal. Chim. Acta. 1990, 236, 222.

12. Golub, M. A.; Weatherson, I. A. In Hummel, H. E.; Miler, T. A., Eds. Springer-Verlag; New York, 1984, p 223.

13. Stenhagen, E.; Abrahamsson, S.; Mclafferty, F. W. John Wiley \& Sons; New York, 1974, 3358 p.

14. Stokes, J. B.; Vebel, E. C.; Warthen, J. D.; Jacobson, M.; Flipen-Anderson, J. L.; Gilardi, R.; Spishakoff, L. M.; Wilzer, K.R. J. Agric. Food Chem. 1983, 31, 1162.

15. Lima, I. S.; Howse, P. E.; Salles, L. A. B. Physiol. Entomol. 1994, 19, 271.

16. Teranishi, R.; Buttery, R. G.; Matsumoto, K. E.; Stern, P. J.; Cunningham, R. T.; Gothilf, S. In Am. Chem. Soc. Symp. Waller, G. R., Ed.; Oklahoma, United States, 1987, p 174.

17. Cross, J. H.; Byler, R. C.; Ravid, U.; Silverstein, R. M.; Robinson, S. W.; Baker, P. M.; Oliveira, J. S.; Jutsum, A. R.; Cherrett, J. M. J. Chem. Ecol. 1979, 5, 187.

18. Brown, W. V.; Moore, B. P. Insect Biochem. 1979, 9, 451.

19. Herbert, R. H. Ph. D. Thesis, University of Southampton, 1981.

20. Baker, R.T.; Herbert, R.H.; Grant, G. G. J. Chem. Commun. 1985, 12, 824.

21. Jang, E. B.; Light, D. M.; Flath, R. B.; Nagata, J. T.; Thomas, R. M. Entomol. Exp. Appl. 1989, 50, 7. 